\title{
Side Strain and Impact Injuries at the Iliac Crest Attachment of Lateral Abdominal Wall Musculature in Cricketers: An Uncommon Injury Pattern
}

\author{
Chinmay P. Mehta ${ }^{1} \quad$ Aditya Daftary $^{1} \quad$ Malini Lawande $^{1}$ \\ ${ }^{1}$ InnoVision Imaging, Mumbai, Maharashtra, India \\ Address for correspondence Dr. Chinmay P. Mehta, Shreenidhi, \\ Above Ishwar Clinic, Shree Krishna Complex, Stella, Vasai (W), \\ Palghar 401202, Maharashtra, India (e-mail: drcm08@gmail.com).
}

Indian J Radiol Imaging 2021;31:373-377.

\begin{abstract}
Side strains refer to injuries of the internal/external oblique or the transversus abdominis, commonly at their attachment to the lower four ribs and rarely at their pelvic attachments. Injuries at the rib attachments are well-described while literature on

Keywords iliac crest attachment injuries is sparse. We report four cricketers who had side strain

- cricket

- iliac crest and direct impact injuries with varying degrees of severity at the iliac crest attach-

- MRI ment. The purpose of this article is to describe the anatomy, possible mechanism of injury, and imaging findings in the lateral abdominal wall muscle injuries at the iliac

- side strain crest, which have not been described previously.
\end{abstract}

\section{Introduction}

The lateral abdominal wall musculature includes three muscles, the external oblique, internal oblique, and transversus abdominis, from superficial to deep. These muscles are predisposed to excessive stresses during torsional/rotational movements of the abdominal wall in activities such as batting, bowling in cricket, and javelin throwing resulting in injuries, usually the proximal attachments. Distal attachment injuries are unusual and there is scant literature on the subject. We also postulate that high velocity impact can result in these injuries at the iliac crest attachment as seen in two of our four patients. The strained abdominal muscles, due to repeated asymmetrical rotational movements would tear on the high impact force, predominantly seen in the recent dynamic shorter formats of the game.

In this study, we describe four unusual cases with side strains affecting the iliac crest attachments of the lateral abdominal wall musculature. We used the modified Peetrons grading ${ }^{1,2}$ system for classification of injuries.

published online

July 27,2021
DOI https://doi.org/

$10.1055 / \mathrm{s}-0041-1734345$ ISSN 0971-3026

\section{Cases}

\section{Case 1}

A 26-year-old all-rounder had an injury during a match while fielding. On site reports from the physiotherapist indicated that the patient landed on the ball when he fell and had localized tenderness on the lower lateral abdominal wall. On magnetic resonance imaging (MRI), the patient had a full thickness, mildly retracted anterior half iliac crest attachment with internal oblique tear extending over a length of $4 \mathrm{~cm}$ anteroposteriorly. The external oblique showed edema, but it was intact and the transversus abdominis was also intact. The upper rib attachments of all three muscles were intact ( - Fig. 1).

After 14 days of observation, the patient underwent autologous platelet-rich plasma injection into the defect under ultrasound guidance. He was rested for 2 weeks, and he returned to play at 28 days. Following the tournament, he underwent continuous physiotherapy and was fully fit at 6 weeks, post injury. The patient underwent sequential MRIs at 20 days post injury ( - Fig. 2 ) with near complete healing at 6 weeks (-Fig. 3). (c) 2021. Indian Radiological Association.

This is an open access article published by Thieme under the terms of the Creative Commons Attribution-NonDerivative-NonCommercial-License, permitting copying and reproduction so long as the original work is given appropriate credit. Contents may not be used for commercial purposes, or adapted, remixed, transformed or built upon. (https://creativecommons.org/licenses/by-nc-nd/4.0/). Thieme Medical and Scientific Publishers Private Ltd. A-12, Second Floor, Sector -2, NOIDA -201301, India 

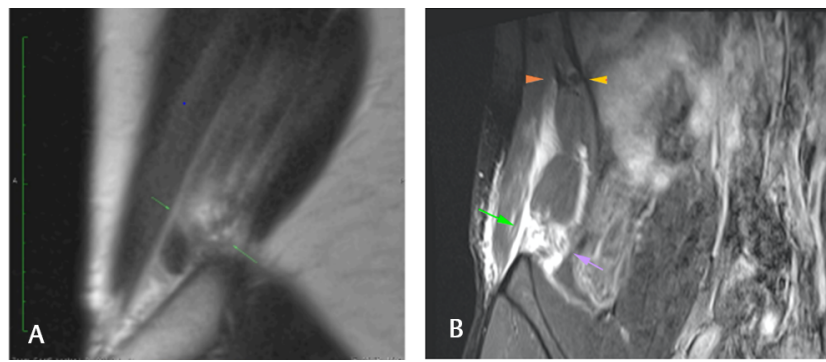

Fig. 1 First set of images after the injury. (A) PD nonfat-suppressed sagittal, (B) STIR coronal. Panels $\mathbf{A}$ and $\mathbf{B}$ demonstrate a full thickness mildly retracted anterior half iliac crest attachment internal oblique tear (arrows) extending over a length of $4 \mathrm{~cm}$. PD, proton density; STIR, short tau inversion recovery.
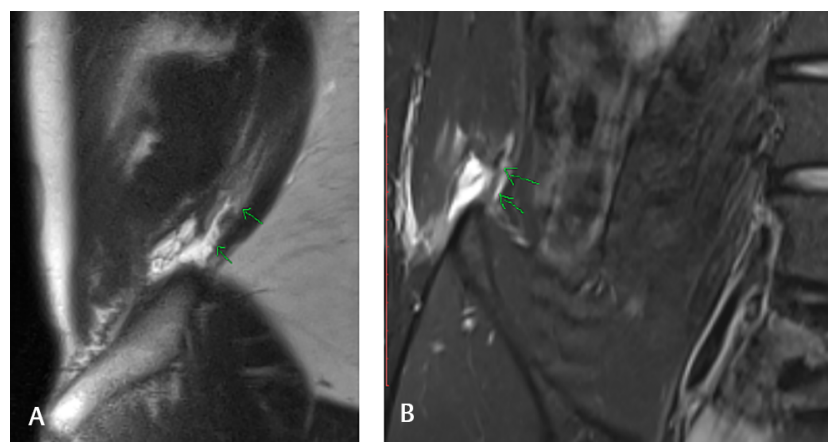

Fig. 2 Three weeks after the injury. (A) PD nonfat-suppressed sagittal, (B) STIR coronal. MRI performed 3 weeks after the injury show early signs of healing with bridging fibers. MRI, magnetic resonance imaging; PD, proton density; STIR, short tau inversion recovery.
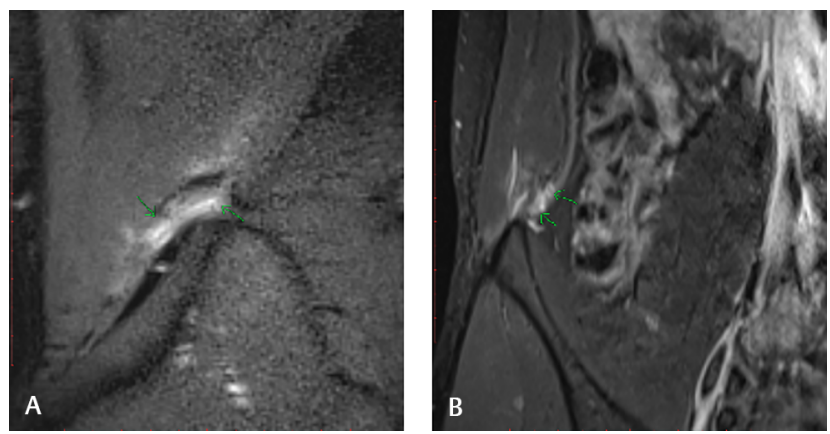

Fig. 3 Six weeks after the injury. (A) T2 fat-suppressed sagittal, (B) STIR coronal, $\mathbf{A}$ and $\mathbf{B}$ show near complete healing with resolution of the defect and retraction (arrows). Only a slender rim of fluid persisted between the iliac crest and the muscle.

\section{Case 2}

A 38-year-old all-rounder had an injury during batting practice, attempting a pull shot across the line to deep midwicket and suffered an intermediate grade injury at the left iliac crest attachment of the internal oblique with mild contiguous edema in the external oblique. No osseous avulsion or significant bone marrow edema pattern was noted. The rib attachments were intact. The player returned to play 10 days after the injury; however, the injury was aggravated, and the MRI was performed. Following the MRI, the player rested for 2 weeks followed by return to play ( - Fig. 4 ).
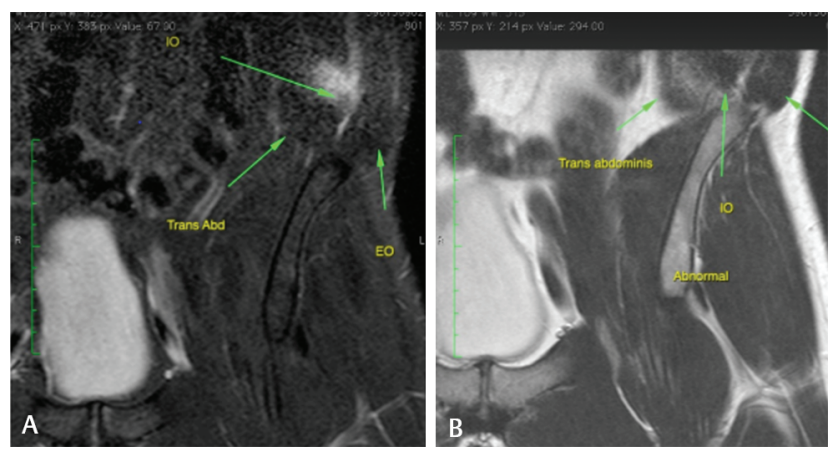

Fig. 4 (A) STIR coronal, (B) PD nonfat-suppressed coronal. MRI images show intermediate grade injury at the left iliac crest attachment of the internal oblique $(\mathrm{IO})$ with mild contiguous edema in the external oblique (EO). No osseous avulsion or significant bone marrow edema pattern was noted. MRI, magnetic resonance imaging; PD, proton density; STIR, short tau inversion recovery.
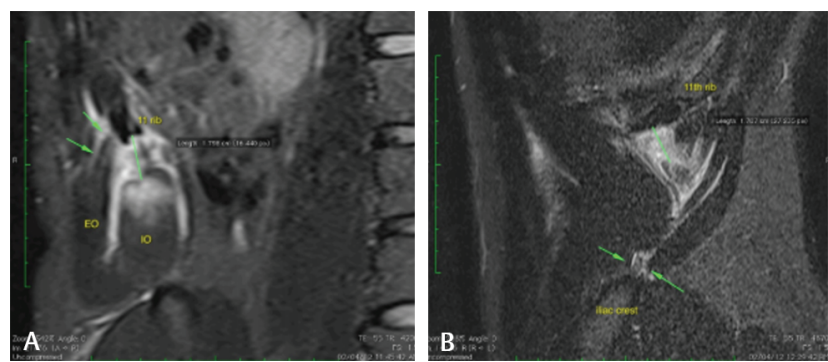

Fig. 5 (A) High-grade internal oblique (IO) injury at the 11th rib costochondral junction attachment with osseous avulsion. Panel (B) demonstrates low-grade internal oblique (IO) injury (arrows) at the iliac crest attachment. EO, external oblique.
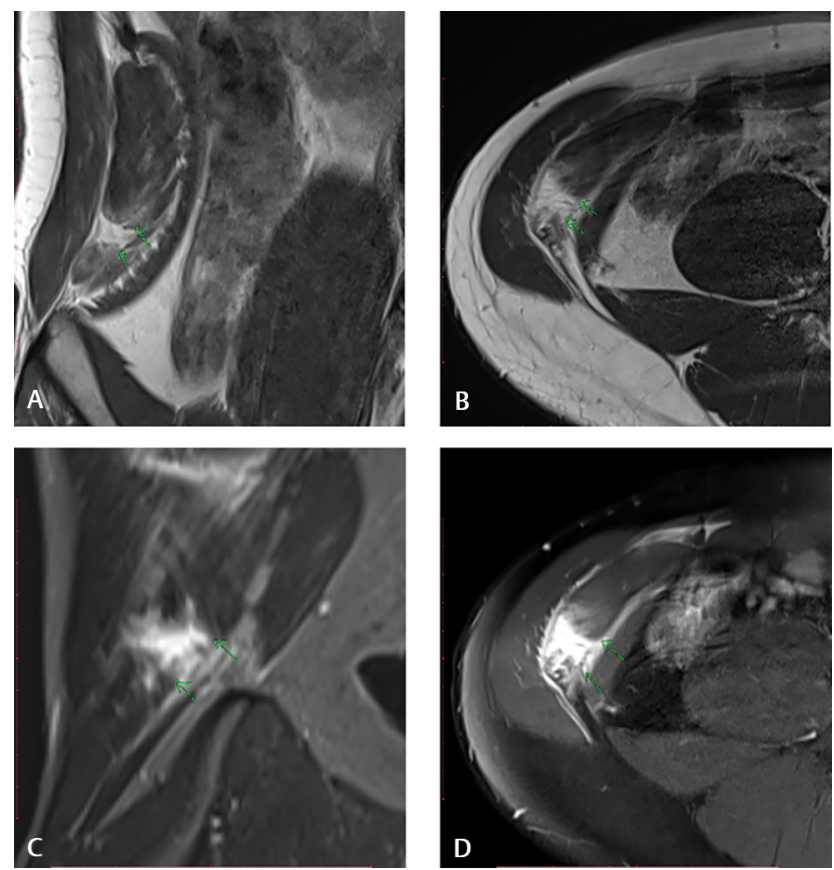

Fig. 6 (A) PD nonfat-suppressed coronal, (B) PD nonfat-suppressed axial, (C) STIR coronal, (D) T2 fat-suppressed axial. (A, D) MRI shows high-grade internal oblique injury just proximal to the iliac crest attachment yielding a retraction of $1.3 \mathrm{~cm}$. MRI, magnetic resonance imaging; PD, proton density. 


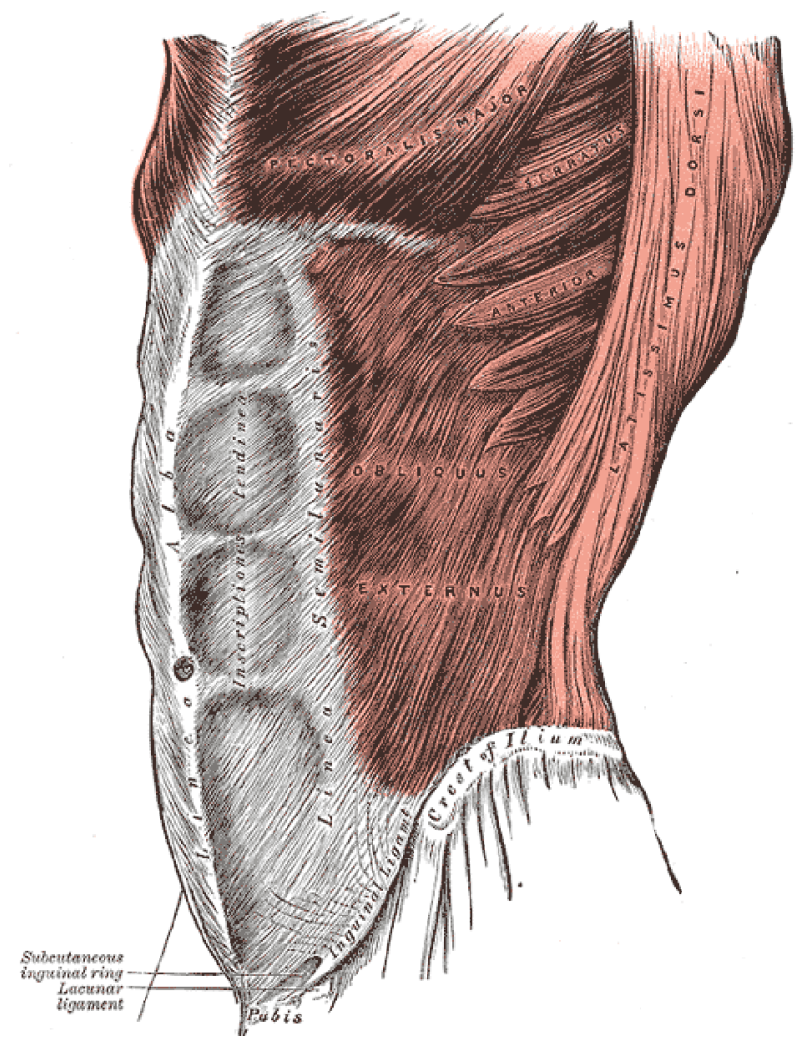

Fig. 7 Graphical anatomy depicting the origin and insertion of external oblique muscle. ${ }^{3}$

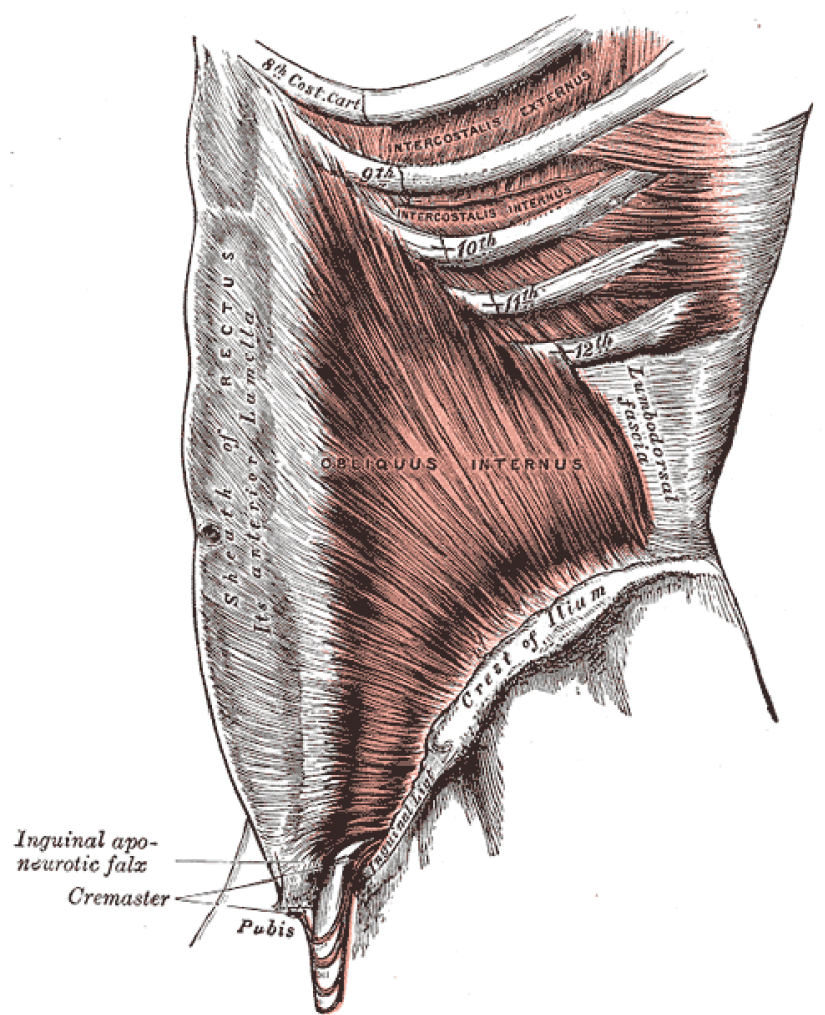

Fig. 8 Graphical anatomy depicting the origin and insertion of internal oblique muscle. ${ }^{4}$

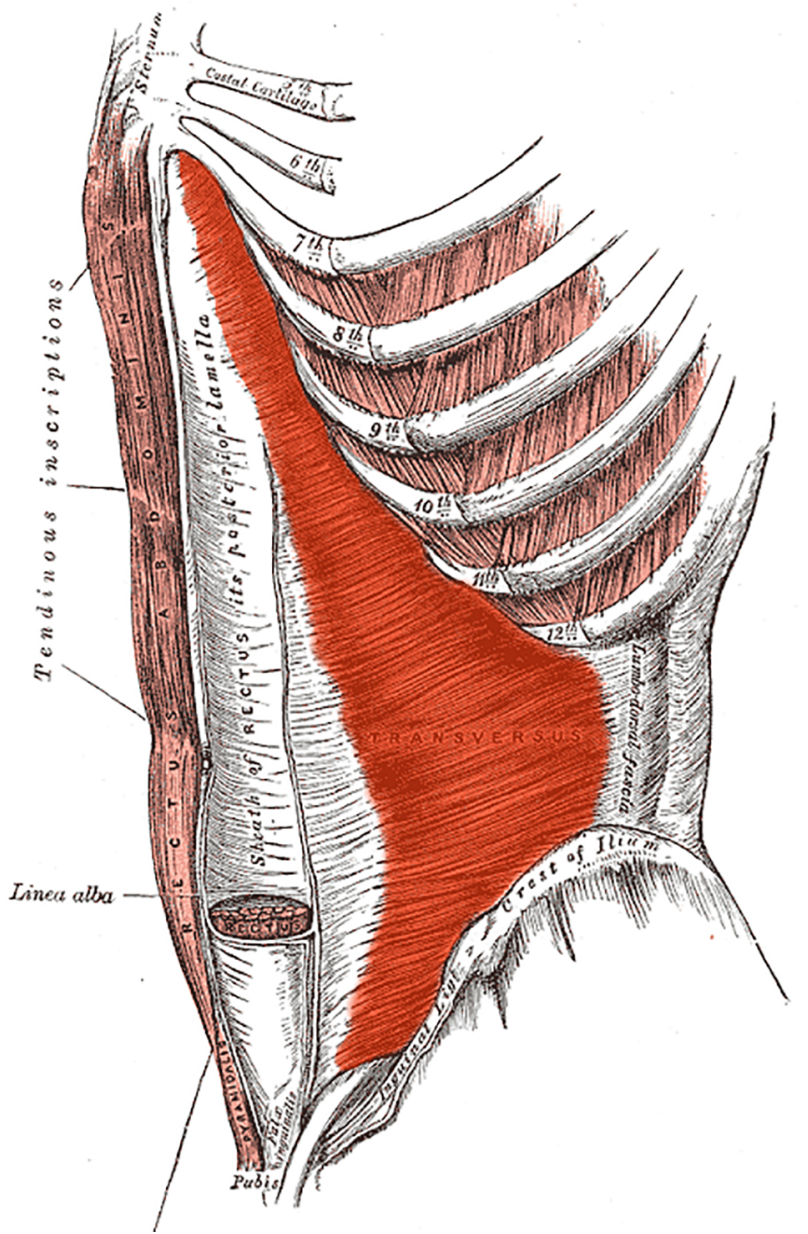

Fig. 9 Graphical anatomy depicting the origin and insertion of transverse abdominal muscle. ${ }^{5}$

\section{Case 3}

A 23-year-old left arm medium pacer suffered low-grade internal oblique injury at the iliac crest attachment and high-grade internal oblique injury at the 11th rib costochondral junction attachment with osseous avulsion. Follow-up and clinical details for this patient were unavailable (-Figs. 5A and B ).

\section{Case 4}

A 30-year-old all-rounder suffered injury while fielding and suffered a high impact fall. He had lower lateral abdominal wall pain. MRI performed demonstrated a high-grade retracted internal oblique injury just proximal to the iliac crest attachment as well as at the inferior end of 11 th rib.

The retraction was $1.2 \mathrm{~cm}$ at the rib attachment and $1.3 \mathrm{~cm}$ at the iliac crest ( - Fig. 6A-D). Patient was rested for 4 weeks, followed by graded physiotherapy for another 4 weeks, before return to play. 


\section{Discussion}

The external oblique, internal oblique, and transversus abdominis form the three key muscles of the lateral abdominal wall. The external and internal oblique muscle fibers run in an oblique direction, perpendicular to each other. The external oblique runs inferomedially from the lower eight ribs superiorly, with lower attachment to the anterior half of the outer lip of iliac crest interiorly and linea alba medially ( $\bullet$ Fig. 7 ). The inferior oblique runs inferolaterally from the inferior borders of 10th to 12th ribs and linea alba with distal attachment to the anterior half of the iliac crest and lat-

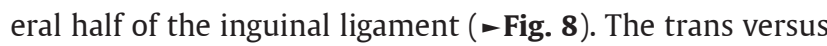
abdominis is the deep muscle of the abdominal wall, beneath the internal oblique. The muscle has inferior attachment from the inguinal ligament, inner lip of iliac crest, superior attachment on the cartilages of the 7th to 12 th ribs and runs transversely to insert into the conjoint tendon, linea alba, and the pubic $\operatorname{crest}^{4}$ (-Fig. 9).

Side strains are a well-known injury of the lateral abdominal wall. ${ }^{6}$ Typically, these injuries happen at the lower rib attachments and involve the internal oblique. ${ }^{7}$ Eccentric contraction of the muscle is felt to be the etiology ${ }^{7.8}$ It is often triggered by unsymmetrical high energy movements. ${ }^{7}$ Torso acts as a foundation with instantaneous high forces produced at the abdominal wall to throw the ball. In the case of cricket fast bowler, the side strain injury happens when the leading arm is aggressively pulled down along with trunk side flexion to generate the force required to deliver the ball at high velocity. ${ }^{7}$ Thus, the oblique muscles are always under a strain in bowlers and all-rounders. We postulate that a sudden high velocity impact on these strained muscles may act as a trigger for the injury as seen in two of our four cases.

Side strains are characterized by a sudden onset of pain and localized tenderness over the lateral trunk near or over the anterior and lateral lower rib cage ${ }^{6,9}$ and less commonly at internal oblique iliac crest attachment following a sudden twisting of the torso. ${ }^{10}$ It is most commonly reported in cricket fast bowlers ${ }^{6,7,11}$ and baseball pitchers, ${ }^{8}$ but in shorter formats of cricket in which we see more inventive batting techniques and more athletic fielding, these injuries also increasingly occur during batting and fielding.

Imaging is opted for when symptoms are significant and decisions regarding injury severity and return to play are needed to be made. ${ }^{7,10}$ MRI is the imaging tool of choice due to its ability to assess muscle and bone. ${ }^{12}$

While rib attachment injuries are well documented, iliac crest attachment injuries are a significantly less common injury pattern and thus far, we have seen only one case report from a player who sustained this injury during Australian Rules football. ${ }^{9}$

We present a series of four cases from a single sport (cricket), which have occurred during three different actions of the game (batting, bowling, and fielding), with injury patterns that involve only the iliac crest attachment of the internal oblique, the internal and to a lesser extent eternal oblique and one that involves both the rib and iliac crest attachments.
From our series, we have found that iliac crest injuries may occur on their own or in co-existence with proximal attachment injuries and etiology ranges from usual forceful contraction to direct impact.

Imaging studies and clinical examination should include both the proximal and distal attachments of the abdominal wall musculature to ensure these injuries are not missed. In cases where symptoms are more significant proximally, a distal injury may co-exist.

In this small study, we found that these patients did not appear to respond differently to patients with only proximal attachment injuries ${ }^{6,7}$ and return to play in the two players who did was within 6 weeks.

\section{Conclusion}

Side strain is a common injury from eccentric loading of the torso and is commonly described at the rib attachments of the internal oblique. Iliac crest attachment injuries demonstrate another variant in the spectrum of this injury. We present four cases in cricket which showed isolated and/or concomitant iliac crest attachment injuries occurring during the actions of batting, bowling, and fielding. Injuries occurred from forceful torsion or direct impact. Return to play times with these injuries does not appear to be different from the more common proximal attachment injuries. We would emphasize scanning the iliac crest attachment in players with suspected side strain injuries.

\section{IRB Waiver}

This was a retrospective research study from our database stored for analysis purposes. We consulted with the IRB of Inno-Vision Imaging who determined that our study did not need an ethical approval and an IRB official waiver of ethical approval was granted.

\section{Financial Support and Sponsorship \\ None.}

\section{Conflict of Interest}

None declared.

\section{References}

1 Peetrons P.Ultrasound of muscles. Eur Radiol 2002;12(1):35-43

2 Ekstrand J, Healy JC, Waldén M, Lee JC, English B, Hägglund M. Hamstring muscle injuries in professional football: the correlation of MRI findings with return to play. Br J Sports Med 2012;46(2):112-117

3 Available at: https://en.wikipedia.org/wiki/Abdominal_ external_oblique_muscle. Accessed August 2020

4 Wikipedia. Internal abdominal obliques. Available at: http:// en.wikipedia.org/wiki/Abdominal_internal_muscle. Accessed August 2020

5 Available at: https://en.wikipedia.org/wiki/Transverse_ abdominal_muscle. Accessed August 2020

6 Connell DA, Jhamb A, James T. Side strain: a tear of internal oblique musculature. AJR Am J Roentgenol 2003;181(6):1511-1517

7 Nealon AR, Kountouris A, Cook JL. Side strain in sport: a narrative review of pathomechanics, diagnosis, imaging and management for the clinician. J Sci Med Sport 2017;20(3):261-266 
8 Kumar S, Narayan Y, Kedka M. An electromyographic study of unresisted trunk rotation with normal velocity among healthy subjects. Spine 1996;21:1500:1512

9 Conte SA, Thompson MM, Marks MA, Dines JS. Abdominal muscle strains in professional baseball: 1991-2010. Am J Sports Med 2012;40(3):650-656

10 Murphy M, Stockden M, Breidahl B. Acute tearing of the oblique abdominal wall insertion onto the iliac crest in an Australian football player: a case report. Int J Sports Phys Ther 2016;11(7):1125-1134
11 Humphries D, Jamison M. Clinical and magnetic resonance imaging features of cricket bowler's side strain. Br J Sports Med 2004;38(5):E21

12 Nealon AR, Docking SI, Lucas PE, Connell DA, Koh ES, Cook JL. MRI findings are associated with time to return to play in first class cricket fast bowlers with side strain in Australia and England. J Sci Med Sport 2019;22(9):992-996 